\title{
Managing the Violent Patient: A Guide for Psychologists and Other Mental Health Professionals
}

\author{
Carl L. Tishler, Lisa B. Gordon, and Laura Landry-Meyer \\ The Ohio State University
}

\begin{abstract}
Being threatened, harassed, attacked, or confronted by a patient with a weapon is becoming more common and is likely to occur at some point in a mental health professional's career. Effective violence management programs can reduce the incidence of violence. Yet, few resources have been provided to assist psychologists and other mental health professionals to deal with aggressive patients. The authors offer strategies for the management of aggressive behavior that can be implemented to empower practitioners to take precautions when necessary in a quick and efficient manner when dealing with violent and potentially violent patients.
\end{abstract}

What would you do if your next patient were violent? Are you prepared to handle a violent patient? Assume your next patient arrives for a scheduled session and you notice a gun in the patient's briefcase. What would you do? Or what if your next patient discloses a plan to injure a coworker and threatens harm to you and your loved ones if the plan is disclosed to anyone, including authorities? How would you handle these situations on a short- or long-term basis?

Rapid and efficient management of violent and potentially violent patients is a critical skill. Violence management is needed by inpatient and outpatient mental health professionals in this era of managed care (i.e., minimal inpatient stays, limited and inexperienced staffing). The pervasiveness of aggression in acute psychiatric and other mental health settings has been documented. Employees staffing one urban psychiatric emergency service identified 99 of 1,806 consecutive patients as violent or potentially violent (Beck, White, \& Gage, 1991). A survey of 300 independent practitioners revealed that $81 \%$ experienced at least one incident of patient physical attack, verbal abuse, or other harassment (Tryron, 1986). Armed police in acute psychiatric facilities and pharmacies, panic buttons, and metal detector searches of patients have become the norm (McCulloch, McNiel, Binder, \& Hatcher, 1986).

Psychologists and other staff often have little or no training regarding the management of potentially violent patients. We

CARL L. TISHLER received his $\mathrm{PhD}$ in counseling in 1977 from the University of Maryland. He is a diplomate in clinical psychology from the American Board of Professional Psychology, an adjunct associate professor in psychology with The Ohio State University, and is in independent practice in Columbus, $\mathrm{OH}$.

LISA B. GoRDON received her $\mathrm{PhD}$ in clinical psychology in 1997 from The Ohio State University, where she is currently the director of the Psychological Services Center.

LAURA LANDRY-MEYER received her $\mathrm{PhD}$ in human development and family science in 1999 from The Ohio State University, where she is currently an adjunct faculty member in the Department of Human Development and Family Science. She is a research associate with Pediatric and Adult Psychologists, in Columbus, $\mathrm{OH}$.

CORRESPONDENCE CONCERNING THIS ARTICLE should be addressed to Carl $\mathrm{L}$. Tishler, 1776 East Broad Street, Columbus, Ohio 43203. Electronic mail may be sent to tishler.1@osu.edu. review the literature pertaining to aggressive patients within psychological and other mental health settings as contexts for the analysis of procedures for managing violent and potentially violent patients on a short-term basis (i.e., while hospitalized, next day or week). We suggest clinical strategies for managing aggressive patients once they are admitted to an acute care setting. These strategies are derived from the current literature to provide a more cohesive, interdisciplinary understanding of patient violence and to develop effective strategies in dealing with these patients.

\section{The Violent or Potentially Violent Patient}

Research in this area has focused on assessing the risk of violence (Harris \& Rice, 1997). A patient's potential for violence has been related to the patient's personal attributes, such as a psychosis (Lion, Snyder, \& Merrill, 1981; Monahan, 1988; Tardiff, 1984), history of violence (Harris \& Rice, 1997; McNiel, Binder, \& Greenfield, 1988), presence of domestic violence (Binder \& McNiel, 1986), social support networks (Estroff, Zimmer, Lachicotte, \& Benoit, 1994), and other demographic characteristics. Recent work has explored situational factors (McNiel, 1998) and the interpersonal relationship between the patient and clinician (Beauford, McNeil, \& Binder, 1997).

Although clinicians may not be able to adequately predict future violence, they must recognize that aggressive behavior is often a symptom of an underlying condition (Harris \& Rice, 1997), and aggressive behaviors will surface in acute care as well as other settings. As Skodol and Karasu (1978) commented, "We are dealing mostly with spontaneously occurring, literally unpredictable events, and the challenge to predict future violence we feel becomes an ever more elusive and fruitless task" (p. 204). Available cues for predicting a patient's potential for violence have been only marginally effective (Apperson, Mulvey, \& Lidz, 1993; McNiel \& Binder, 1987; Skodol \& Karasu, 1978). Recently, actuarial or statistical methods have been used in predicting violence and have been found to be more reliable than a clinician's judgement of a patient's aggressive behaviors (Harris \& Rice, 1997).

Psychologists and other mental health professionals must recognize that specific diagnostic procedure to identify violent or potentially violent patients may not always be accurate or feasible. 
As McNiel (1998) stated, "The relationship between psychiatric diagnosis and violence is controversial" (p. 99). It is within this context that attention toward the role of the psychologist and specific intervention or management strategies are made.

\section{The Psychologist or Mental Health Professional}

The role of the psychologist or other mental health professional is key "in a violence management program. The nature of the practitioner-patient relationship is a product of the ongoing interaction between the patient and psychologist and has the potential to affect the patient's behavior and the professional's work role. For instance, individuals with a mental illness who included a mental health professional in their social support network were less likely to be violent (Estroff et al., 1994). Evidence has been found showing that a "weak therapeutic alliance during initial patient evaluation, increased risk of a patient exhibiting physical attack or fear-inducing behavior in the first week of hospitalization" (Beauford et al., 1997, p. 1274). The characteristics of the mental health setting may negatively affect the therapeutic alliance. For instance, if the initial evaluation occurs in an acute setting, the rapid pace of the acute care facility combined with the impaired communication of patients in crisis often impedes the complete assessment of even mediocre cues for predicting violence (Travin \& Bluestone, 1994). In urgent care settings, the intense workplace environment combined with possible distaste for violent patients may erode amicability between patient and professional, which may impede a professional's ability to avoid conflict with potentially unreasonable patients (Dubin, 1990). The nature of the patient-professional relationship has the potential to mediate violent behavior.

Legal and ethical considerations arise in the professionalpatient relational context. Statutes and court cases (e.g., Tarasoff $v$. Regents of University of California, 1974, 1976) impose the "duty to warn" on practitioners (Eddy \& Harris, 1998). With this legal and ethical (American Psychological Association, 1992) mandate, the management of a violent or potentially violent patient takes on greater significance. For instance, a violent or potentially violent patient who has been prescribed involuntary hospitalization or medication is likely to be angry and frightened, which may increase aggressive tendencies (Monahan, 1988; Tardiff, 1996b). Laws regarding outpatient treatment of violent or potentially violent patients are unclear, and the constitutionality of the standard of legal mechanisms for providing involuntary treatment for individuals who are violent has been debated (Slobogin, 1994). The outpatient practitioner's role to warn inpatient facilities takes on greater urgency if the patient has been previously violent or has violent tendencies. A clinical example of the interactionist nature of the patient-professional relationship embedded in the context of legal and ethical obligations are offered by Carl L. Tishler:

The hospital psychiatrist informed me of the adolescent patient's threats as the patient was released from the hospital. I proceeded to protect myself by contacting law enforcement authorities. Despite attempts to notify law enforcement, I was told to go to three different police jurisdictions: (1) hospital location, (2) adolescent patient's residence, and (3) my residence. In each case, no attempt was made to offer me adequate protection from the potentially violent patient due to jurisdictional issues.
Duty to warn is further complicated by society's general unpreparedness to handle violent psychiatric patients. A practitioner's judgement concerning violent tendencies may not be accurate (Harris \& Rice, 1997) but it must be reported. Apprehension in the prescription of involuntary hospitalization may be exacerbated as mental health practitioners are increasingly concerned with safety, which is evidenced by nearly half of all psychotherapists being threatened, harassed, or physically attacked at some point in their careers (Guy et al., 1992). Psychotherapists' concerns about patient behavior ranged from unwanted calls to physical and verbal attacks on self and loved ones to murder of self and loved ones (Flannery, Hanson, Penk, \& Flannery, 1994). Professionals who experience problems or difficulties in their professional lives (i.e., aggressive patients) tend to compromise their abilities to function adequately in their professional roles (Sherman \& Thelen, 1998). Young or inexperienced psychologists and other mental health professionals can be considered more at-risk for these detrimental effects than others.

Safety precautions increase only when distress associated with aggressive patients increases. In fact, violence management training was typically taken after a violent episode (Guy et al., 1992). Annual staff trainings typically include global safety issues in quality assurance reviews (Black et al., 1994) rather than individual training that focuses on personal security. Mental health professionals seldom receive verbal or written information regarding personal security. Perhaps it is indicative of training programs' minimal consideration of violence management that psychiatrists experience greater incurrence of assault in the early phases of their careers (Carmel \& Hunter, 1991; Tardiff, 1996b). We propose that greater dissemination of information regarding personal security issues within an acute psychiatric setting would contribute to a reduction in the incidence of patient violence.

\section{Clinical Strategies: Management of Aggressive Behavior}

The following suggested strategies are for psychologists and other mental health professionals to manage rapidly and efficiently a violent or potentially violent patient within the context of an acute care facility. Inferences and applications can be made to other mental health settings. These strategies are intended to be guidelines, not a prescription for universal treatment of aggressive behavior. The current article represents an attempt to contribute to the literature regarding the management of aggressive patients and to fill the existing conceptual gap in training.

\section{Initial Assessment}

Safety precautions should be taken when approaching patients to initiate the assessment process. First, clinicians should slowly approach patients from the front or side rather than from behind so as not to startle them. An adequate patient-clinician distance should be maintained as patients with assaultive tendencies surround themselves with greater buffer zones or personal boundaries. Second, clinicians should mirror a patient's body language to communicate empathy with his or her current state and control of the situation. For example, clinicians should sit with seated patients, stand with standing patients, and walk alongside pacing patients. A clinician who towers over seated patients conveys both intimidation and an unwillingness to learn about the patients' 
plight. Being seated while patients are standing makes the clinician vulnerable to violent attacks. Walking alongside patients offers willingness to learn about the patients' agitated behavior and illustrates mutual understanding. Third, clinicians should introduce themselves as clinicians, that is, as members of a helping profession. Repetitively identifying oneself and one's objectives as benign often ensures that even disoriented, emotionally aroused, or intoxicated patients may retain this information (Eichelman, 1995; Tardiff, 1991, 1996b).

In the initial assessment phase, typically, clinician and patient walk to an evaluation room. En route to the evaluation room, the safest walking stance for clinician and patient is lateral. Clinicians lagging behind patients may incite suspicion or paranoia or precipitate fear-inducing behavior, whereas clinicians forging ahead allow patients clear access to assault them. Assault attacks have been found to take place in corridors rather than in other locations in an acute hospital or medical center setting (Balderstone, Negley, Kelly, \& Lion, 1990; Lanza, Kayne, Hicks, \& Milner, 1994). Care should be taken at all times with potentially violent patients regarding movement and actions.

\section{Evaluation Environment}

In the evaluation room, clinicians should continue to practice violence prevention measures during the course of the assessment. Clinicians place themselves in considerable peril when they deny the potential for violence within each patient. Assaultive patients have vastly heterogeneous demographic and diagnostic characteristics (McNiel \& Binder, 1987; Tardiff, 1992). Overestimating one's ability to recognize violent patients merely impedes clinicians from adequately protecting themselves through safe conduct and thorough assessment (Dubin, 1995; Eichelman, 1995).

Choosing an appropriate physical environment is part of a violence management program and is a safety precaution. Evaluation room arrangements vary in privacy: a closed versus open door and staff outside versus present (Tardiff, 1996b). Optimal evaluation environments balance extreme privacy or clinician isolation from swift assistance and extreme visibility or overstimulation for an already harried patient (Dubin, 1995). Evaluation rooms designed with unobtrusive observation windows with safety glass offer direct observation of a clinician with a violent or potentially violent patient. In environments where this type of observation is not possible, staff should be assigned to monitor outside the room and provided with a written set of guidelines to intervene in a violent or potentially violent situation. Clinicians should choose a setting in which they feel comfortable, for clinicians' anxieties may both exacerbate patients' agitation and interfere with clinicians' thorough assessments.

Evaluation rooms should not contain flimsy furniture or heavy objects (e.g., ashtrays, medical instruments) that patients can hurl (McNiel, 1998) or lighting fixtures that fracture into shards when broken. Conversely, ideal evaluation settings afford soft objects such as pillows that may substitute as shields (Tardiff, 1992), sufficient space for five staff members to execute restraint procedures, two doors so that clinicians can exit despite a patient's barricading one doorway, and a panic button to indicate the clinician's jeopardy to outside personnel.

The interpersonal context of the assessment within the evaluation environment should also be considered. Clinician and patient should remain minimally an arm's length from each other (Dubin, 1990) and maintain appropriate personal boundaries consistent with ethical codes of conduct (American Psychological Association, 1992). Clinicians should sit closer to the evaluation room door so that they can exit quickly should patient violence ensue (Tardiff, 1991). Clinicians should monitor their physical appearance in the context of the evaluation room. Potential safety hazards include rings, dangling pierced earrings, lank necklaces, draped stethoscopes, eyeglasses, and neckties (McNiel, 1998). Violent patients may seize such items when disoriented, enraged, or panicked, and injure the practitioner (Dubin, 1995; Eichelman, 1995; Tardiff, 1996b).

\section{Assessment Process}

The assessment for the risk of violence parallels the assessment of any symptom. The evaluation should include histories of violence, family, patient development, physical health, mental status examination, physical examination, and laboratory tests (McNiel, 1998). Multiple sources should, when possible, be obtained to document past history of violence and tendencies toward violent behavior. Sources may include patient disclosure, police officers' verbal and written reports, family members' accounts, patients' therapists and medical physicians, and past medical records (Tardiff, 1992). Although clinicians hesitate to question patients about their tendencies toward violence (Rada, 1981), the most effective prevention against assault is a thorough knowledge of the patient's history of violence (Binder \& McNiel, 1986).

Crucial details that a clinician may investigate to learn about a patient's history of violence include (a) chronology of violent episodes from onset to present; (b) target(s) of violent behavior; (c) severity of injury or intended injury from violence; (d) associated symptoms surrounding a violent episode; (e) ownership and use of weapons and weaponry skills; (f) criminal and impulsive behaviors such as destruction of property, reckless driving, suicide attempts, and self-mutilation remnants that may include cigarette burns, scars, and self-made tattoos (Dubin, 1995; Pastor, 1995; Tardiff, 1992); and ( $\mathrm{g}$ ) severity of violent injuries sustained by the patient or severity of violent injuries sustained by the victim of the patient.

In assessing a patient's family history, a critical target is the occurrence of assault within the family environment because children who endure abuse are more likely to become violent adults (Pastor, 1995). A review of a patient's medical history reviews both psychiatric and medical illnesses as well as possible previous violent episodes. Questions exploring psychiatric illness focus on the occurrences of psychotherapy, psychiatric hospitalization, and prescriptions for psychotropic medication. Questions exploring medical illness aim to establish certain diagnoses such as substance intoxication or withdrawal, head trauma, Alzheimer's disease, mental retardation, and a vast array of additional medical diagnoses that may possibly induce aggressive behavior (Pastor, 1995).

In addition to obtaining detailed violence, family, and medical histories, clinicians should conduct mental status examinations. A thorough mental status examination allows the clinician to investigate delusions and hallucinations; delirium associated with neurological disease; signs of substance intoxication or withdrawal such as slurred speech, uncoordinated movements, dilated or constricted pupils, tremors, the smell of alcohol, and organic disrup- 
tion of higher cognitive capacities. Finally, clinicians should conduct routine laboratory tests (Dubin, 1995) in order to help provide an accurate diagnosis and subsequent management and treatment for the patient. These tests could include a toxicology screen (blood and urine monitored for alcohol and drug), an electroencephalogram (EEG), magnetic resonance image (MRI), and other tests if a specific disorder is suspected, such as heavy metal screening to detect poisoning (Tardiff, 1992).

\section{Personal Reaction to a Violent or Potentially Violent Patient}

Clinicians should attempt to manage their negativity and fear in reaction to patients' odd or frightening behaviors. A fearful or hostile reaction to a patient can negatively impact the professional-patient relationship in terms of open communication, trust, and rapport building. Clinicians can curtail hostile reactions to a patient's bizarre behaviors by first recognizing that such behaviors are merely symptoms of a patient's underlying illness (Harris \& Rice, 1997). Next, clinicians should present a calm demeanor regardless of their actual level of fear. A clinician's discomfort may exacerbate a patient's agitation (Dubin, 1990). The personal fear of the clinician may be diminished through open discussion with patients and identification of threatening patient behavior (see discussion about verbal intervention). Strategies to abate a patient's sense of helplessness, and thereby a patient's dependence on intimidation tactics, should be used.

When fearful of personal safety, clinicians should implement a personal safety plan. The implementation of the plan should incorporate the notification of staff members in a professional and calm manner. Follow the safety precautions outlined previously during the assessment process and the evaluation environment. Components of the plan should prioritize the safety of all individuals and may include summoning help by activating an alarm system or a phone call to local authorities. Protective measures should be developed on the bases of the clinical environment, availability of staff members, the presence of security alarm system, and relationship with local law enforcement agencies.

\section{Creating Rapport}

Clinicians should institute several measures to create a respectful, supportive context when interviewing patients. Empathy may be conveyed to the patient through "active" listening (Eichelman, 1995). This listening should be unbroken by logical reasoning as to the error of patients' delusions and hallucinations, urgent requests for factual information, and premature interpretation of patients' narratives. Active listening guidelines include engaged eye contact and body language to convey attention, compassion, paraphrasing the patient's speech to indicate that the clinician has understood the patient, and honesty as to the likely future happenings to the patient while in the emergency setting (Eichelman, 1995).

\section{Restraint Strategies}

Restraint strategies may be needed in order to conduct a patient assessment. Specific guidelines regarding the appropriate and safe use have been developed (American Psychiatric Association, 1985). Restraint strategies may take one of three forms: verbal, physical, or pharmacological (Travin \& Bluestone, 1994). Clinicians should choose among these restraint types, carefully using the degree of danger patients present to personnel and to themselves as a guide.

Verbal intervention focuses on setting limits (McNiel, 1998). Verbal intervention may constitute an appropriate means of restraint for patients without psychosis or organic impairment (Tardiff, 1996b) as well as other patients whose potential for violent behaviors were not assessed to be high. Verbal intervention may be suitable for patients who look physically agitated, issue a threat, or confront a clinician with a weapon.

Clinicians who verbally intervene with a potentially violent patient should practice similar guidelines as outlined earlier for interviewing a patient (e.g., maintaining adequate personal space, approximating patient's stance). Moderate eye contact and nonthreatening body language are both important. Clinicians should avoid insistent eye contact because it may appear confrontational, and lack of eye contact may put the patient ill at ease.

When employing a verbal intervention strategy, clinicians should calmly approach patients, followed by a verbal acknowledgment without disdain or sarcasm of a patient's obvious agitation (e.g., "You look angry"). The clinician should then grant the patient "permission" to express anger and helplessness uninterrupted. The anger may take the form of debasing the clinician, who must be prepared to tolerate the critical onslaught. During this dialogue, the clinician may present the patient with a choice, such as to take medication. By offering a choice, the patient becomes invested with a modicum of control.

Verbal intervention is also an effective strategy for any patient who issues a threat. "Threats are messages that require comment; to ignore them is to give a message that you do not care, that you are indifferent to suffering, or that you are disdainful" (Lion, 1995, pp. 51-52). When a patient makes a serious threat, clinicians have a legal (McNiel, 1998) and ethical (American Psychological Association, 1992) duty to protect the intended victim of a threat. Clinicians must make the assessment if the threat is serious and if the threat poses a risk. If the threat is deemed serious and poses a risk, clinicians should follow the inpatient safety procedures established by the mental health facility.

When presented with a threat, a clinician's response should follow a logical sequence. First, verbal intervention should acknowledge the confrontation ("Your words are threatening and causing me fear"); followed by an interpretation ("Your words push people away"); expression of one's own reactions ("Your words make me angry, and I cannot help you when I feel like that"); and followed by an advisement ("Police are routinely called when patients issue threats"). Responding to a patient's threat is crucial, for such a response conveys that the patient's threat affected its intended goal, possibly rendering greater violence unnecessary (Lion, 1995).

Verbal intervention is an appropriate strategy when patients confront clinicians or staff with weapons. Between $4 \%$ and $8 \%$ of patients bring weapons with them to psychiatric emergency rooms (McNiel, 1998; McNiel \& Binder, 1987). Screening for weapons prior to entrance into a facility is one intervention strategy that should not be overlooked (McCulloch, McNiel, Binder, \& Hatcher, 1986) and should be systematically applied (McNiel \& Binder, 1987) to ensure a weapon-free environment (Black et al., 1994). When confronted with patients who have weapons, profes- 
sionals who verbally calmed their patients tend to suffer fewer instances of bodily injury and property damage than if verbal or physical aggression were used (Dubin, Wilson, \& Mercer, 1988). Approaching an armed patient should be made with a neutral acknowledgment of the situation (e.g., "I see you have a gun"; Tardiff, 1996b). Clinicians should refrain from reaching for the weapon or commanding the patient to relinquish the weapon. These measures may result in injury because of gun discharge and may heighten a patient's sense of anger, helplessness, and ineptitude. Clinicians should admit fear to convey humanness, express a desire to help the patient, explore the feelings of inadequacy and passivity underlying the patient's possession of a weapon, and request that the patient redirect the weapon to allow the clinician to focus on the patient's distress (Dubin, 1995).

If the patient eventually agrees to surrender the weapon, the clinician should not reach for it but ask the patient to place the weapon on the floor; patients may construe reaching for the weapon as taking the weapon, which may appear confrontational or threatening. Precautions should be made to ensure the patient does not have additional weapons. Clinicians should ask patients whether they have additional weapons with them, and if so, request that these weapons be placed on the floor as well. Once all weapons have been placed on the floor, the clinician and patient should go to another room, leaving the weapon(s). The clinician should tell another staff person in front of the patient that a weapon was left in the room by the patient. Directing another staff person to confiscate the weapon in front of the patient provides an openness with the patient, acknowledging the weapon threat as well as to alert staff of the patient's possession of a weapon.

Physical restraint and seclusion frequently offer the greatest protection to clinicians and patients, especially when chosen and implemented properly. Physical restraint should not compose a form of punishment or a tool of convenience and should not be handled without additional staff assistance. Patients who are unlikely to respond to verbal intervention may be good candidates for physical restraint and/or seclusion. Seclusion may benefit manic or psychotic patients who require decreased sensory stimulation (Tardiff, 1996a). Clinicians should not prescribe seclusion for patients in whom sensory deprivation could exacerbate delirium (Lion, Madden, \& Christopher, 1976) or for patients who have overdosed or have self-mutilation tendencies, both of whom require vigilant monitoring (Tardiff, 1996a).

The procedure involved in the use of physical restraints should be initiated with ample staff, as a show of force often engenders compliance (Dubin, 1990) and ensures a humane, rapid, and safe physical restraint (Eichelman, 1995). In a team-oriented approach, a restraint leader would select at least four additional staff members and assign each member a patient's extremity to restrain. The team leader would focus on the control of the patient's head. The path from the patient to the seclusion room should remain clear. On first contact with the patient, the restraint leader should present the reason for physical restraint and calmly request that the patient enter the seclusion room accompanied by staff members. If after a few seconds the patient fails to comply, each staff member should seize the assigned body part, lower the patient to the ground in a backward motion, and restrain each extremity at its joint. The restraint leader should control the patient's head to prevent a neck injury and the patient from biting a staff member. Once in the seclusion room, staff members should remove the patient's poten- tially dangerous clothing items and belongings, such as rings, belts, shoelaces, and matches. The physical restraint procedure is not a vehicle for practicing carelessness, humiliation, or intimidation (Tardiff, 1996b). Leather restraints are the wisest choice for physically restraining patients, as they avoid injuring the patient's skin and withstand violent movement without tearing or decreasing the patient's blood circulation, unlike cloth restraints.

Similar to physical restraint, decisions to institute pharmacological restraint or pharmacotherapy should be made cautiously. Pharmacological restraint or control uses sedatives or other drugs to diminish aggressive behavior (Harris \& Rice, 1997). Emergency medication should diminish a patient's violent displays without inducing a stupor (Tardiff, 1991) and can offer significant usefulness with a violent patient. Pharmacological restraint may be used in tandem with physical restraint and/or seclusion.

Rapid tranquilization (RT) is a type of pharmacological restraint consisting of varying doses of neuroleptic medication at 30-to-60min intervals, with core symptoms of restlessness and psychomotor agitation generally subsiding (McNiel, 1998). As Dubin (1990) explained, "The goal of RT is to calm patients so that they can cooperate in their evaluation, treatment, and disposition. Sedation is not necessarily a desired end" (p. 505).

The psychologist and other physician members of the emergency team all need an understanding of RT and its positive and potentially negative consequences. Two basic strategies exist for RT, which are namely, high-potency neuroleptic medication, plus a sedating agent if necessary, or low-potency neuroleptic medication, which contains both antipsychotic and sedative properties (Tardiff, 1991). Caution should be taken as "over medication with sedating neuroleptics or minor tranquilizers may worsen the situation by exacerbating the patient's feeling of loss of control" (Conn \& Lion, 1984, p. 880). When implementing a pharmacological restraint, clinicians may offer patients an oral form of medication or administer the drug intramuscularly. Clinicians who present patients with the oral choice afford greater patient involvement in treatment and prevent the sense of helplessness, invasion, and pain frequently concomitant with the intramuscular administration (Dubin, 1990). In a crisis situation, patients usually require neuroleptic medication intramuscularly.

Psychologists should be aware that the use of tranquilizer medications may compound a patient's problems if the patient has taken a large quantity of a particular substance, such as a street drug (e.g., PCP) or alcohol. The clinician, prior to making a decision regarding a pharmacological restraint, must wait until laboratory test results (e.g., toxicology) are obtained or reliable history can be obtained from the patient's friends and/or family regarding the use of substances or history of substance abuse. The laboratory tests are initiated during the assessment process. Psychologists should work hard with the other team members to use psychological or physical restraint methods while waiting for the test results necessary prior to the rapid tranquilization. These methods may include orienting the patient and reassuring the patient. If physical restraint is required, letting the patient squeeze two fingers (not more) is sometimes reassuring to the patient. Clinicians need to remove all rings during this procedure as a precautionary measure. These psychological methods should be practiced by all emergency setting team members involved with violent or potentially violent patients. 
In the administration of a pharmacological restraint, several precautionary steps should be taken. If the etiology of violence is unknown, clinicians should refrain from chemical restraint (Tardiff, 1992). The possibility of delirium, toxic metabolic state (Soloff, 1987), or masking of the violence may be precipitants in these cases. Patients with delirium or other organic impairments should not be candidates for rapid tranquilization because the neuroleptic effects may worsen these conditions. Third, clinicians should not administer chemical restraint to patients intoxicated with alcohol or other depressant agents, for the combination of neuroleptic medication and such agents may endanger a patient's level of consciousness. Similarly, if a patient is withdrawing from alcohol, then RT should not be used because it reduces the seizure threshold (Tardiff, 1996a).

\section{Admitting or Transfer Procedures}

After the assessment process, and when the violent tendencies have subsided, the patient may be admitted to the hospital or transferred to another facility. If the patient initially entered a general hospital, fewer than one quarter of all hospitals have separate psychiatric units, making referral to another treatment setting most likely (Travin \& Bluestone, 1994). Safety precautions should be taken to ensure a nonviolent transition to the next phase of the patient's treatment. To assist with this transition process, the clinician should teach introductory techniques to the professionals involved in the next phase of the patient's treatment.

First, the clinician should always speak clearly and in the presence of the patient. Second, the clinician should verbalize that the patient was initially acting out but is now calm ("Patient was being verbally-physically threatening, but is now okay"). The clinician who verbally acknowledges the violent tendency and the patient's current composed state, provides professionals involved in the patient's future care with a warning as well as reinforcing the patient's current demeanor. Clinicians have the duty to warn (American Psychological Association, 1992; Eddy \& Harris, 1998) and must do so at all phases in the patient treatment process.

Next, the clinician should state any concerns regarding the patient. For instance, the clinician may have a fear that during transportation to another facility the patient may try to escape ("Patient may try to jump out of the car during transportation"). By acknowledging this concern in front of the patient and the other professionals involved, the duty to warn has been achieved while also reducing the risk of the event occurring. When the patient and professionals are aware of a risk, the risk of occurrence is reduced. Effective management of the violent and potentially violent patient includes the safe transfer of the patient's treatment to another professional.

\section{Conclusion}

Patient violence is common in inpatient and outpatient mental health settings. The lack of education and training for psychologists and other mental health professionals regarding the management of potentially violent clients can lead to detrimental outcomes for the clinician and patient (e.g., physical injury, death). Psychotherapists are considered at-risk for occupational violence, and homicide is the cause of $12 \%$ of deaths in the workplace (Pastor, 1995). In this article, we suggest clinical strategies for managing aggressive patients in the acute care setting. These strategies are offered to more adequately assess and address the risk of patient violence as well as to provide clinicians with practical useful information.

Violence is difficult to predict. The therapeutic relationship between clinician and patient can modulate violence if the clinician understands the nature of the therapeutic alliance and the management of violent and potentially violent patients. A clinician who ignores or diminishes a patient's violent tendencies may experience legal, ethical, professional, and personal consequences. The patient may potentially injure himself, the clinician, or others. Nonmanagement of violent behavior denies appropriate treatment to patients and lowers the effectiveness of patient treatment. Clinicians' hesitancy to address violence in acute settings, regardless of reasonable explanation, simply serves to generate future violence. Not all violence can be prevented, but with instruction, precaution, and training, violence can be successfully and effectively managed.

\section{Implications for Practice}

Violence management must become a critical part of training programs at institutional and professional levels. Acute care educators and clinicians need to discuss violence before it occurs and implement a plan for its management in all inpatient and outpatient settings. As Travin and Bluestone (1994) stated, "The best type of management of any potentially violent patient lies in prevention" (p. 111). With sufficient education and execution of safe conduct within an acute setting, staff may expend more energy and efforts in healing patients rather than recovering from violent episodes.

Acute care settings should establish a written policy regarding violent and potentially violent patients. All staff should be required to have adequate training and be required to comply with established policy. Panic buttons should be installed and locations should be marked. Guidelines concerning the procedures to deal with a violent patient who makes threats or who has a weapon should be posted and accessible to all staff. If weapons are a particular concern, metal detector searches may be a possible strategy. In an era of managed care and the trend to reduce staff, concern arises that violent incidents tend to occur when there is a lower staff-patient ratio (Black et al., 1994; Lanza et al., 1994). Precautions, such as metal detectors or the presence of armed and trained security, may constitute a strategy if low staff rates are a concern. These precautions should not be considered alternatives to adequate staffing, training staff members in patient violence, and an established policy in the management of violent patients.

Staff should be instructed to recognize warning signs of violence in a patient (Tardiff, 1992) and required to comply with established policy regarding patient violence (Black et al., 1994). Awareness about potentially violent behavior through education and training is critical as the incidence of violence increases.

Educational and training programs should address global as well as personal security issues. Research linking safety concerns and professional ability (Sherman \& Thelen, 1998) provide evidence of the concern and need for more instruction on violence management. In one study, the most frequent protective measure taken by psychotherapists to protect themselves from patient-initiated physical harm was the refusal to treat certain patients (Guy et al., 1992). An example from Carl L. Tishler illustrates this finding: 
An adolescent patient became suicidal and was involuntarily hospitalized after making a suicide attempt. I made the decision to involuntary hospitalize with a consensus from the adolescent patient's parents. During the involuntary hospitalization and in the course of treatment with the lead hospital psychiatrist, the adolescent patient made threats indicating his intent to physically harm or kill the hospital psychiatrist and myself for the involuntary hospitalization. The adolescent patient was released from the hospital because of his potentially violent nature.

Refusal to treat is an ethical and legal dilemma and should not be considered a component of a violence management program. Training in the management of assaultive behaviors was cited by only $15 \%$ of psychotherapists as a protective measure (Guy et al., 1992). Training programs in the management of violence should be proactive, occurring before a violent episode with a patient.

It is reported that nearly half of all psychotherapists are threatened, physically attacked, or harassed by patients at some point in their careers (Guy et al., 1992). Would you be prepared if a violent episode were to happen to you? Be prepared for aggressive patients. A violence management program has the potential to reduce the incidence of patient violence, increase a sense of personal security among staff, and provide better patient care. The strategies presented offer a foundation on which to develop a violence management program by focusing on appropriate assessment, interaction, and safety procedures in order to empower staff to take precautions when necessary in a quick and efficient manner.

\section{References}

American Psychiatric Association. (1985). Seclusion and restraint: The psychiatric uses (Task Force Report No. 22). Washington, DC: Author. American Psychological Association. (1992). Ethical principles of psychologists and code of conduct. American Psychologist, 47, 1597-1611.

Apperson, L. J., Mulvey, E. P., \& Lidz, C. W. (1993). Short-term clinical prediction of assaultive behavior: Artifacts of research methods. American Journal of Psychiatry, 150, 1374-1379.

Balderstone, C., Negley, E. N., Kelly, G. R., \& Lion, J. R. (1990). Data-based interventions to reduce assaults by geriatric inpatients. Hos. pital and Community Psychiatry, 41, 447-449.

Beauford, J. E., McNeil, D. E., \& Binder, R. L. (1997). Utility of the initial therapeutic alliance in evaluating psychiatric patients' risk of violence. American Journal of Psychiatry, 154, 1272-1276.

Beck, J. C., White, K. A., \& Gage, B. (1991). Emergency psychiatric assessment of violence. American Journal of Psychiatry, 148, 15621565.

Binder, R. L., \& McNiel, D. E. (1986). Victims and families of violent psychiatric patients. Bulletin of the American Academy of Psychiatry and the Law, 14, 131-139.

Black, K. J., Compton, W. M., Wetzel, M., Minchin, S., Farber, N. B., \& Rastogi-Cruz, D. (1994). Assaults by patients on psychiatric residents at three training sites. Hospital and Community Psychiatry, 45, 706-710.

Carmel, H., \& Hunter, M. (1991). Psychiatrists injured by patient attack. Bulletin of the American Academy of Psychiatry and the Law, 19, 309-316.

Conn, L. M., \& Lion, J. R. (1984). Pharmacologic approaches to violence. Psychiatric Clinics of North America, 7, 879-886.

Dubin, W. R. (1990). Psychiatric emergencies: Recognition and management. In A. Stoudemire (Ed.), Clinical psychiatry for medical students (pp. 497-526). Philadelphia: Lippincott.

Dubin, W. R. (1995). Assaults with weapons. In B. Eichelman \& A. C. Hartwig (Eds.), Patient violence and the clinician (pp. 53-72). Washington, DC: American Psychiatric Press.
Dubin, W. R., Wilson, S. J., \& Mercer, C. (1988). Assaults against psychiatrists in outpatient settings. Journal of Clinical Psychiatry, 49, $338-345$.

Eddy, S., \& Harris, E. (1998). Risk management with the violent patient. In P. M. Kleespies (Ed.), Emergencies in mental health practice: Evaluation and management (pp. 217-231). New York: Guilford Press.

Eichelman, B. S. (1995). Strategies for clinician safety. In B. Eichelman \& A. C. Hartwig (Eds.), Patient violence and the clinician (pp. 139-154) Washington, DC: American Psychiatric Press.

Estroff, S. E., Zimmer, C., Lachicotee, W. S., \& Benoit, J. (1994). The influence of social networks and social support on violence by persons with serious mental illness. Hospital and Community Psychiatry, 45, 669-678.

Flannery, R. B., Hanson, A., Penk, W. E., \& Flannery, G. J. (1994). Violence against women: Psychiatric patient assaults on female staff. Professional Psychology: Research and Practice, 25, 182-184.

Guy, J. D., Brown, C. K., \& Poelstra, P. L. (1992). Safety concerns and protective measures used by psychotherapists. Professional Psychology: Research and Practice, 23, 421-423.

Harris, G. T., \& Rice, M. E. (1997). Risk appraisal and management of violent behavior. Psychiatric Services, 48, 1168-1176.

Lanza, M. L., Kayne, H. L., Hicks, C., \& Milner, J. (1994). Environmental characteristics related to patient assault. Issues in Mental Health Nursing, 15, 319-355.

Lion, J. R. (1995). Verbal threats against clinicians. In B. Eichelman \& A. C. Hartwig (Eds.), Patient violence and the clinician (pp. 43-52). Washington, DC: American Psychiatric Press.

Lion, J. R., Madden, D. J., \& Christopher, R. L. (1976). A violence clinic: Three years experience. American Journal of Psychiatry, 133, 432-435.

Lion, J. R., Snyder, W., \& Merrill, G. L. (1981). Underreporting of assaults on staff in a state hospital. Hospital and Community Psychiatry, 32, 497-498.

McCulloch, L. E., McNiel, D. E., Binder, R. L., \& Hatcher, C. (1986). Effects of a weapon screening procedure in a psychiatric emergency room. Hospital and Community Psychiatry, 37, 837-838.

McNiel, D. E. (1998). Empirically based clinical evaluation and management of the potentially violent patient. In P. M. Kleespies (Ed.), Emergencies in mental health practice: Evaluation and management (pp. 95-116). New York: Guilford Press.

McNiel, D. E., \& Binder, R. L. (1987). Patients who bring weapons to the psychiatric emergency room. Journal of Clinical Psychiatry, 48, 230233.

McNiel, D. E., Binder, R. L., \& Greenfield, T. K. (1988). Predictors of violence in civilly committed acute psychiatric patients. American Journal of Psychiatry, 145, 965-970.

Monahan, J. (1988). Risk assessment of violence among the mentally disordered: Generating useful knowledge. International Journal of Law and Psychiarry, 11, 249-257.

Pastor, L. H. (1995). Initial assessment and intervention strategies to reduce workplace violence. American Family Physician, 52, 11691174.

Rada, R. T. (1981). The violent patient: Rapid assessment and management. Psychosomatics, 22, 101-105.

Sherman, M. D., \& Thelen, M. H. (1998). Distress and professional impairment among psychologists in clinical practice. Professional Psychology: Research and Practice, 29, 79-85.

Skodol, A. E., \& Karasu, T. B. (1978). Emergency psychiatry and the assaultive patient. American Journal of Psychiatry, 135, 202-205.

Slobogin, C. (1994). Involuntary community treatment of people who are violent and mentally ill: A legal analysis. Hospital and Community Psychiatry, 45, 685-689.

Soloff, P. H. (1987). Emergency management of the violent patient. In R. E. Hales \& A. J. Frances (Eds.), Psychiatry update: American 
Psychiatric Association annual review (Vol. 6, pp. 510-536). Washington, DC: American Psychiatric Press.

Tarasnff v. Regents of the University of California. 118 Cal. Rptr. 129, 529 P. 2d. 553 (Cal. 1974).

Tarasoff v. Regents of the University of California. 17 Cal. 3d, 425, 555 P. 2d. 334 (1976)

Tardiff, K. (1984). Characteristics of assaultive patients in private hospitals. American Journal of Psychiatry, 141, 1232-1235.

Tardiff, K. (1991). Violence by psychiatric patients. In R. I. Simon (Ed.), American Psychiatric Press review of clinical psychiatry and the law (Vol, 2, pp. 175-233). Washington, DC: American Psychiatric Press.

Tardiff, K. (1992). The current state of psychiatry in the treatment of violent patients. Archives of General Psychiatry, 49, 493-499.

Tardiff, K. (1996a). Advances in the treatment of violent patients. In F. L.
Mak \& C. C. Nadelson (Eds.), International review of psychiatry (Vol. 2, pp. 121-142). Washington, DC: American Psychiatric Press.

Tardiff, K. (1996b). Concise guide to assessment and management of violent patients (2nd ed.). Washington, DC: American Psychiatric Press.

Travin, S., B Bluestone, H. (1994). Managing violent patients throughout the general hospital: Some clinical, legal, and administrative concerns. Psychiatric Annals, 24, 107-113.

Tyron, G. S. (1986). Abuse of therapists by patients: A national survey. Professional Psychology: Research and Practice, 17, 357-363.

Received July 9, 1998 Revision received June 16, 1999 Accepted July 16, 1999 